\title{
La sociedad creativa debe superar la distopía
}

Francisco Menchén Bellón ${ }^{1}$

https://orcid.org/0000-0002-0034-6373

\section{Resumen}

Es urgente solucionar los problemas que acarrea una sociedad distópica, como la que vivimos en la actualidad. En un mundo globalizado es imprescindible promover una sociedad creativa, donde el ciudadano pueda vivir de acuerdo con su verdadera naturaleza. Generar una sociedad creativa es caminar hacia un horizonte justo, integral, y humano; debe contemplar las 5 s: Sana, Sostenible, Sensible, Solidaria y Sinérgica, características básicas si pretendemos innovar, cooperar y compartir a todos los niveles. Para ello, hemos rescatado el concepto de Homo creator, único camino para alcanzar la plenitud de vida. Igualmente consideramos esencial incorporar en los centros docentes el sentido de la Responsabilidad Social Corporativa y conectar con la Naturaleza y devolverle todos sus poderes naturales. Invertir en el futuro significa actualizar y ponderar el I + D + i. La ciencia y la innovación son fundamentales para enfrentarse a grandes retos sociales y para encontrar soluciones a los problemas complejos.

Palabras claves: Sociedad creativa, Distopía, Espiritualidad, Empoderar. Responsabilidad social corporativa.

\section{Creative society must overcome dystopia}

\section{Abstract}

It is urgent to solve the problems that a dystopian society brings, like the society in which we live today. In a globalized world it is essential to promote a creative society, where citizens can live according to their true nature. To generate a creative society is to walk towards a fair, comprehensive and human horizon; this creative society must have the $5 \mathrm{Ss}$ : Healthy (Sana in Spanish) Sustainable, Sensitive, Solidary and Synergistic, basic characteristics if we intend to innovate, cooperate and share at all levels. For this, we have rescued the concept of Homo creator, the only way to achieve fullness of life. Likewise, we consider it essential to incorporate in schools the sense of Corporate Social Responsibility and connect with Nature and restore all its natural powers. Investing in the future means updating and weighing $\mathrm{I}+\mathrm{D}+\mathrm{i}$. Science and innovation are essential to face great social challenges and to find solutions to complex problems.

Keywords: Creative society, Dystopia, Spirituality, Empower, Corporate social responsibility.

\footnotetext{
${ }^{1}$ Maestro y licenciado en Psicología y en Ciencias de la Educación. Ha sido inspector de Educación. Ha conseguido varios premios nacionales de Investigación Educativa, el premio Barcelona de la Sociedad Espańola de Psicología, el premio del Ministerio de Educación y Ciencia y el premio AEDIPE HUMAN 2003. Actualmente Curator de Creatividad. fcomenchen@yahoo.com.
} 


\title{
Introdução
}

\author{
"La creatividad es como la electricidad, \\ siempre está ahi, pero necesita conectarse y encenderse y, \\ en ocasiones, producir la corriente poderosa lleva tiempo" \\ FRANCISCO MENCHÉN (2009, 5).
}

¿Sabes que la Biblia dice que somos hechos a la imagen de Dios, el Dios que inventó la creatividad, entonces nosotros también somos creativos?

En estos tiempos inciertos, desconcertantes y turbulentos que nos ha traído COVID-19 nos encontramos inmersos en una realidad de cambios sociales vertiginosos que, para el mundo educativo requiere recuperar, conscientemente, una gran parte del espíritu creativo. Para descubrir la nueva manera de estar en el mundo, el gran desafío que tienen los centros educativos y la universidad, es encontrar una alegría, una motivación, una estrategia y un entusiasmo profundo que persista pese a los altibajos de la vida.

Estos cambios son tan profundos y se producen a tal velocidad que es fácil perder el ritmo a la hora de gestionar el futuro. No hay que olvidar que ningún docente está aislado, que cada uno desde su puesto está entretejido en una red vibrante, aunque él no sea consciente. Una red que es como una Web de interrelaciones de todo tipo: psicológicas, emocionales y mentales. Debemos tomar conciencia de la importancia que tiene conocer nuestra consciencia interior y despertar de nuestros condicionamientos que nos permita sintonizar con el lenguaje y la cultura que ha de inspirar a esa sociedad creativa a la que aludo.

Para dar sentido, relevancia y fiabilidad a este artículo, he rastreado la historia de la humanidad tratando de encontrar un escenario similar al que estamos viviendo actualmente, por causa del Covid-19. Al final, he encontrado en el siglo XV un joven escritor italiano que hizo un "Discurso sobre la dignidad del hombre" que, vivió en su tierra el estallido de la denominada peste negra. Se trata de PICO DELLA MIRANDOLA (14631494).

Este autor prototipo del hombre del Renacimiento, conocido como el "Conde de la Concordia" piensa que la dignidad tiene su causa en Dios, creador de un ser extraordinario, capaz de devenir lo que él mismo se propone. El resto de la creación tiene marcado su destino. Tiene una naturaleza fija, 
salvo el hombre. Dirigiéndose a Adán, el primer hombre, pone en boca del Todopoderoso...

"Te he puesto en el centro del mundo, para que puedas observar cuanto hay en él. No te he hecho de materia celestial ni terrenal, ni mortal ni inmortal, para que conforme a tu libre albedrío y tu dignidad, puedas darte la forma que elijas. A ti te ha sido concedido el poder de degradarte hasta el nivel de las formas inferiores de vida, el de las bestias, $y$ a ti te ha sido concedido el poder, albergado en tu intelecto y en tu juicio, de reencarnarte en las formas superiores, las divinas".

Ningún autor hasta entonces, había pensado la libertad con tanta profundidad, pues no se trata de una libertad para obrar, sino, más bien, para ser. Este mensaje será el inspirador de esa sociedad creativa que tenemos que construir todos juntos, si estamos dispuestos a superar esta distopia tan turbadora que vivimos.

Este mensaje coincide plenamente con la famosa frase inscrita en la entrada del templo de Apolo en Delfos "conócete a ti mismo". Precisamente SÓCRATES, el más sabio entre los hombres, en el siglo $\mathrm{V}$ a. C. ya adoptó este lema en su nuevo método de enseñar en el ágora.

Hace miles de ańos que los sabios de la antigüedad nos recordaron que todo lo que buscamos se encuentra en nuestro interior, y que era necesario despertar el hambre por aprender a gestionar nuestra autoestima. Con este "click" mental, FRANCISCO MENCHÉN recupera un concepto olvidado: homo creator, con la intención de crear una sociedad creativa que pueda superar todos las dificultades y problemas de una humanidad que vive en plenitud.

Estos tres grandes pilares serán los que sustentarán un nuevo renacimiento que insufle energía a la nueva sociedad creativa, fruto de una Nueva Humanidad, que tenemos que construir entre todos, basados en una Responsabilidad Social Corporativa (RSC) de cada uno de los miembros de este Nuevo Orden Educativo, cuyo germen ya está aquí.

El éxito de una sociedad creativa estriba en vivir de acuerdo a nuestra verdadera naturaleza, no conforme al pensamiento de otros o los presuntos ideales que impone la sociedad. La felicidad de un ciudadano que vive en una sociedad creativa dependerá de saber utilizar al máximo los talentos que la naturaleza le ha dispensado. Hemos de hacer las cosas con pasión, por el placer

${ }^{2}$ Citado por ZYGMUNT BAUMAN (2016, 80/81). 
de hacerlas, porque la excelencia es nuestro estilo, no por acumular más o por sobrevivir.

\title{
Generar una sociedad creativa
}

\author{
"La razón por la que estamos en este mundo \\ es para interactuar de forma creativa" \\ WILIAM OLAF STAPLEDON (1886-1937) \\ (Filósofo británico)
}

¿Sabes que la orquesta del TITANIC, el barco de los sueños, siguio tocando hasta que el barco se hundió? Los músicos decidieron no interrumpir de tocar a pesar de la tragedia.

La globalización y los avances tecnológicos han cambiado para siempre la forma de permanecer en el mundo en el que vivimos. Ignorar esta realidad no solo sería una insensatez, sino que en la actualidad sería, sencillamente, inviable, pues estamos absorbidos por estos factores de tal manera, que no podemos mantenernos al margen.

Generar una sociedad creativa es caminar hacia un horizonte justo, integral, y humano. Es urgente solucionar los problemas que conlleva vivir en un mundo globalizado, hiperconsumista que vive de espalda a la naturaleza. Es tiempo de asumir la responsabilidad de nuestra vida, nuestro trabajo, nuestros proyectos y disolver los obstáculos que, en la mayoría de los casos, nosotros mismos hemos construidos.

Si creamos alumnos creativos, tendremos escuelas creativas, y es a partir de estos primeros pasos cuando se puede conseguir una sociedad creativa. La materia prima de este proceso hay que buscarla en el niño y en la niña y ofrecerle una educación acorde con estos tiempos en continuos cambios; ellos deben ser educados de forma holística, es decir en sus tres dimensiones: corporal, mental y espiritual. La autorrealización llega cuando se armonizan estas capacidades de forma coherente.

Una sociedad creativa no puede tener miedo a explorar lo desconocido, si sus impulsos imaginativos se despiertan; los ciudadanos debemos tener la libertad y la decisión de pasar esa línea que separa lo posible de lo imposible. Es en ese espacio donde está la clave para alcanzar el estado divino, atributo negado a los humanos. No se puede olvidar que, cualquier tipo de 
incertidumbre implica riesgo, pero es el compañero inseparable de cualquier acción novedosa.

Una sociedad creativa debe integrar las 5 Ss: ser Sana, de tal forma que, permita convivir todos los seres humanos, sin ningún tipo de exclusión; ser Sostenible, a fin de promover los principios que permitan el progreso social, el equilibrio medioambiental y el crecimiento económico; ser Sensible, de tal modo que pueda aportar valor ańadido a las personas; ser Solidaria, de tal manera, que los problemas y dificultades se resuelvan con la participación, la ayuda y el compromiso de todos; y ser Sinérgica, por lo que, deben crear rutas bien definidas que ayuden a innovar, cooperar y compartir a todos los niveles.

Generar una sociedad creativa trae consigo transformar los actuales sistemas educativos y socioeconómicos, necesarios para afrontar los retos de una sociedad global e hiperconectada, donde han dejado de ser válidas las soluciones del pasado. Los problemas complejos que hoy tenemos encontrarán respuestas compartiendo información y conocimiento con los diversos actores que constituyen la sociedad. Sin compartir no puede haber justicia social, sin justicia no puede haber paz, y sin paz no puede haber futuro.

Estamos ante el nacimiento de una nueva sociedad creativa, una brillante civilización y una cultura cosmopolítica, donde compartir, cooperar y comprometerse han reemplazado a la codicia, la competencia y el egoísmo. En el nuevo escenario ha de predominar el arte de saber ser, saber compartir y saber crear tu propia realidad.

\section{Superar la distopia}

"Nuestros sueños son nuestra segunda vida: soy incapaz de cruzar los portones que nos llevan al mundo invisible sin sentir escalofrios" PAULO COELHO

¿Sabes que cuando GUTENBERG inventó la imprenta se soliviantaron los amantes de los manuscritos y los defensores del pergamino se rebelaron contra el papel?

La distopía, es un mundo en el que nada es perfecto; está basada en una reflexión teórica difícil, pero además injusta y no deseable por las consecuencias que de ella se derivan. El Diccionario de la Lengua española la define en los términos siguientes: "Representación ficticia de una sociedad futura de características causantes de la alienación humana" 
La distopia, entendido como "lugar malo", está relacionada con eutopía, que indica algo positivo o favorable, donde habita una humanidad ejemplar. Las tradiciones espirituales suelen dividir a los seres humanos en dos grandes grupos: los que sacan de su consciencia lo peor de sí mismo; y los que extraen lo mejor de ella.

Si examinamos con detalle la situación actual de la cultura y la educación, la sanidad, las tecnologías, la ecología y el medio ambiente, la economía y la política, observaremos, claramente, que ya estamos en una sociedad distópica. Es muy real y está aquí presente entre nosotros, avanzando y tomando cuerpo en muchas facetas de nuestra vida cotidiana. Durante los próximos lustros se irá consolidando a escala mundial y global.

ZYGMUNT BAUMAN (2015), creador de la modernidad líquida, considera que la sociedad puede ser manipulada con intenciones y ambiciones perversas y falsificadas, como se aprende en 1984 del escritor británico GEORGE ORWELL, el más leído en estos tiempos. El brillante sociólogo polaco escribe en su obra la Ceguera moral: "El cuidado de la salud del cuerpo social requiere cirugia intensiva: las partes enfermas (o propensas a la enfermedad) han de ser amputadas) $(2015,57)$.

El gran pensador hace un duro diagnóstico de la desigualdad y la falta de sentido colectivo en un mundo individualista, subrayando que la riqueza de unos pocos no beneficia a todos. Argumenta a partir del concepto de "adiáfora" que rescata de la cultura escolástica, y que para él significa "irrelevante". Explica que estamos "en peligro de perder nuestra capacidad de comprender lo que sucede en el mundo y empatizar con quienes sufren" (BAUMAN, 2015, 58).

La virtud es irrelevante en un mundo donde se hace cualquier cosa para lograr un minuto de gloria; donde la banalidad se ha apropiado de la vida pública, y donde la insatisfacción se ha adueñado de todo. GRETA THUMBERG, activista sueca de 16 años, lo ha expresado muy bien: el planeta se encuentra en grave peligro y el genero humano está amenazado como los dinosaurios.

Esta visión viene a representar una indiferencia a los problemas y a las vicisitudes de la existencia. Este peligro existe en una vida cuyo ritmo está dictado por las guerras de audiencia, en un tiempo en que la información envejece antes de asentarse. Nos apresuramos bajo la "tiranía del momento" que nos ofrece pocas oportunidades para memorizarlo y conservarlo en el recuerdo. Estamos atormentados por la fragilidad del presente que exige una base firme que no tenemos. 
El caos global que estamos experimentando ahora no es una coincidencia ni tampoco es algo casual sino tiene una causalidad: la civilización tal como la conocemos está llegando a su fin y está empezando a germinar una Nueva Humanidad, - no "nueva normalidad" como nos dicen -. STEPHEN HAWKING dejó escrito en su libro póstumo Breves respuestas a las grandes preguntas que el gran desafío que se nos presenta es el papel del ser humano ante la nueva realidad.

Esto significa, que nuestra sociedad está en declive y debemos renunciar de lamentaciones, miedos y sufrimientos, y empezar a entender la vida como creadores y dejar de sentirnos víctimas. Todo dependerá de nosotros y tendremos que rediseñar nuestras costumbres, nuestros patrones y nuestras creencias, según queramos construir una sociedad creativa o una sociedad anestesiada y errática.

Para superar esta distopia que estamos padeciendo, debemos dejar lo viejo y abrazar lo nuevo; debemos ser sońadores y aprender a movernos por espacios invisibles; debemos dejar de ser víctimas y empezar a ser creadores. La agitación planetaria que estamos experimentando no es un final, sino un nuevo comienzo, un nuevo germen que nos ofrece la oportunidad de dar a luz un nuevo ser humano. Hay que asegurar que la existencia humana pueda seguir prosperando en el futuro.

La ciencia de vanguardia nos da la clave para superar esta distopia. Según los últimos descubrimientos de la neurociencia, la biofísica cuántica y la epigenética vienen a mostrar que, la consciencia nos permite ser creadores y estamos facultados para controlar nuestra genética y manifestar nuestras experiencias de vida a través del auto-empoderamiento.

La nueva manera de entender los centros docentes en el mundo será elegir la vía de auto-empoderamiento y sacar hacia fuera lo mejor que hay dentro de cada uno, y ponerlo al servicio de todos los miembros que componen la comunidad. Cuando se dan estas circunstancias los maestros y profesores pueden ejercer la voluntad de ir más allá de su zona de confort y explorar nuevos territorios que les permitirá innovar y reinventarse.

Plan noe: nuevo orden educativo

"El mundo como lo hemos creado es un proceso de nuestro pensamiento. No puede ser cambiado sin cambiar nuestro pensamiento" ALBERT EINSTEIN 
¿Sabes que las abejas han constituido una sociedad anónimavirtual para cobrar facturas millonarias por los servicios de la polinización?

La crisis del Covid-19 se ha apoderado del mundo, y en casi todas las esferas de la vida se ha manifestado de distinto modo. Según explica HANNAH ARENDT, famosa filósofa alemana, las crisis se convierten en desastre solo cuando respondemos a ellas con juicios preestablecidos. Tal actitud agudiza la crisis y nos quita la ocasión de reflexionar sobre la realidad que brinda. Una crisis de esta envergadura nos obliga a volver a plantearnos nuevas preguntas y nos exige nuevas respuestas.

El Plan NOE está inspirado en el pensamiento de ZYGMUNT BAUMAN, sociólogo polaco, célebre por configurar la vida a través del pensamiento líquido, denunciando la insensibilidad moral y el deterioro progresivo de nuestra sociedad. Igualmente se fundamenta en la filosofía que emana de la Responsabilidad Social Corporativa compromiso que tienen las organizaciones con la sociedad en la que se ubican.

Este Nuevo Orden Educativo responsabiliza a los equipos directivos, a los docentes y a la comunidad educativa de velar por la misión, la visión y los valores que identifican a cada uno de los centros de enseñanza. Estos principios deben cumplir cualquier tipo de institución, sea universitaria o no universitaria, público o privado; sus funciones abarcan el desarrollo del medio ambiente sostenible, la justicia social y los códigos éticos de funcionamiento. Esta alternativa posibilita crear un sistema en red, en lugar de estructuras jerárquicas ya caducas.

El objetivo prioritario consiste en promover una sociedad creativa multidisciplinar, más justa, responsable, sostenible, adiáfora e integradora. No podemos permitir que nos sigan manipulando nuestro entorno social, banalizando la cultura, promocionando el hiperconsumismo, deteriorando nuestra dignidad y no prestar atención a los temas importantes de la existencia humana.

Si observas el mundo a cierta distancia, observarás que la mayoría de la población está preocupada por consumir para seguir viviendo, a través de adquirir nuevos productos, más y más. Parece ser que estamos regidos por una ley que dice: si no hay consumo no hay vida, no hay riqueza. Estamos hipnotizados por nuestras creencias. 
Este Plan NOE se preocupa por el desarrollo humano en todas sus dimensiones, pero que también incluye otras variables que contempla el capital social, el capital natural y el capital económico, todos ellos necesario para la sostenibilidad del planeta.

Construir un capital social comunitario permite co-crear un proyecto de salud mental, donde todos los protagonistas estén implicados, y así evitar el deterioro progresivo de nuestra sociedad. Debemos contagiar a las nuevas generaciones de alumnos de actitudes de empatía, criterios éticos y coherencia cardiaca y cerebral.

Comprende también un "capital natural" que promueva el valor de la Naturaleza para evitar la extinción de la especie humana. Los ciudadanos vivimos en nuestro planeta Tierra y somo consumidores de energía no alimentaria, importante para realizar todas las funciones corporales, fundamental para el crecimiento. Sin vida no hay sociedad ni hay economía.

Además, una sociedad creativa debe promover la innovación, y para ello se necesita el capital económico. Esta variable juega un papel importante a la hora de pensar que tipo de ciudades y pueblos queremos Se trata de buscar la formula que nos permita cierta calidad de vida.

La sociedad creativa derivada de esta crisis global debe replantearse la importancia que tiene invertir en innovación. Los responsables de las autonomías, las ciudades y los pueblos deben poner a trabajar a los científicos y a la ciencia. Sirva como ejemplo el caso de Israel, que a finales del siglo XX era considerado como un país pobre, y decidió como política de Estado ir por el camino de la ciencia. Actualmente invierte el $4 \%$ del PIB en ciencia, tecnología e innovación, mientras que España dedicó el año 2018 el 1’24 \%.

Invertir en el futuro significa actualizar y ponderar el I + D + i como lo ha hecho Uruguay, apoyando la actividad científica y creando el CIVE (Centro de Investigación en Vigilancia Epidemiológica). La ciencia y la innovación son fundamentales para enfrentarse a grandes retos sociales y para encontrar soluciones a los problemas complejos. El principal determinante para el desarrollo y transformación de la economía de un país es generar procesos innovativos.

El Plan NOE representa una energía nueva que busca nexos que permitan nutrir, equilibrar y colaborar en lugar de competir, destruir y enfrentarse. Para ello, he transformado la Responsabilidad Social Corporativa en una plataforma que proyecte los tres pilares que han de constituir el Nuevo Orden Educativo con el objeto de conseguir una buena conciliación de la vida personal, profesional y familiar. Para ello me guiaré por la letra inicial de cada termino: 


\section{$\bullet \mathrm{R}-\mathrm{R}$ ED \\ $\bullet S$ - S UEÑOS \\ -C - C REATIVIDAD}

Propongo generar en todos los docentes una plataforma fundamentada en una RED DE SUEŃOS CREATIVOS que haga despertar a todos los implicados del condicionamiento tan brutal que nuestra sociedad nos ha enganchado. Estamos hipnotizados y no somos conscientes.

Los valores tradicionales de tiempos pasados ya no nos proporcionan la guía, ni la ilusión, ni la seguridad que necesitamos para rentabilizar el esfuerzo y la dedicación que exige actualmente el desarrollo comprometido de nuevos proyectos educativos multidisciplinares. Hay un dicho popular que dice: "Si no cambiamos la dirección en la que caminamos, acabaremos alli a donde nos dirigimos"

Posiblemente tendremos que empezar a cambiar la cultura de los centros docentes, empezando por Educación Infantil hasta llegar a la Educación Universitaria, y tener en cuenta que todo lo que hacemos palabras, ideas, acciones, sentimientos y emociones - tiene un efecto sobre el entorno, un karma diría un budista. Este comportamiento responde a la ley universal de causa y efecto: no existe acción sin causa, ni tampoco causa sin acción.

Además, si queremos alcanzar una sociedad creativa, debemos cuidar otra fuerza que mueve la vida, conocida por dharma, que trae orden a la consciencia individual, cuando actúas correctamente y atiendes tu dimensión espiritual. Este concepto indio viene a significar el deber que tienes para realizar tu vida interior y mejorar tu calidad de vida. El dharma se trabaja en la vida presente, mientras el karma afecta a la vida futura.

Según mi experiencia, tengo que afirmar que, para desarrollar una sociedad creativa más justa, además. es imprescindible apuntalar, especialmente, la dimensión espiritual desde los primeros años de escolaridad, enseñanza poco presente en la práctica cotidiana. Un niño se autorrealiza cuando en su perfil de identidad figuran valores como la paz, la conciencia, la honradez, la justicia social y el amor.

No podemos seguir viviendo en un mundo de ciegos porque se ahogan nuestros sueños. No podemos seguir viviendo una cultura de masa vacía porque nuestra dimensión espiritual desaparece. Nuestra civilización está 
perdida en el hacer y no sabe nada del Ser, solo cuenta el movimiento hacia fuera y se olvida que, lo esencial es promover una apertura hacia el interior, para poder conectar con la consciencia universal.

SATURNINO DE LA TORRE $(2019,101)$, gran conocedor de la acción educativa a nivel internacional, manifiesta que los centros educativos son el reflejo de esta sociedad competitiva y hedonista, que se centra en transmitir conocimientos en lugar de ayudar a pensar, promover valores humanos, sociales, solidarios y medioambientales; recomienda promover la resiliencia y las actitudes, habilidades y competencias que le serán útiles para la vida. En suma, desarrollar el espíritu creativo y emprendedor.

En nuestras relaciones con los miembros de nuestra comunidad existen todas las potencialidades, pero debido a nuestra actitud, solo algunas llegan a manifestarse. Se trata de una experiencia de consecuencias muy sutiles, pero que quedan grabadas en nuestro cuerpo y ejercen influencias en los demás y afectan a los resultados. Hay un adagio popular que dice: "Lo que un hombre siembra, será lo que coseche”. Planta las mejores semillas y obtendrá los mejores resultados para tu colegio, instituto o facultad.

La sociedad creativa debe despertar nuestra espiritualidad y descubrir esa fuerza interna que supla a la debilidad humana; así alcanzaremos el yo superior que trasciende. Una vez que encontramos la consciencia pura surgirá el amor cósmico y el amor a todos los seres vivos. Debemos recordar nuestro origen y escuchar el movimiento armónico de la divinidad de la vida. Para vivir el Paraíso en la Tierra tenemos que humanizar lo divino y divinizar lo humano.

\section{Reflexiones para compartir}

"Ser creativo

tendría que ser un derecho humano básico universal que corresponda a todos los hombres y mujeres, y que figurase en el frontispicio de todas las escuelas. En el futuro los docentes convivirán en una relación basada en la cooperación amistosa y no en la competitividad, así como en la generosidad y confianza mutua y no en la rivalidad.

FRANCISCO MENCHEN (2015)

¿Sabes que VICTOR FRANKL, creador de la Logoterapia, pensaba que, el sentido de mi vida es ayudar a que otros encuentren su sentido? 
Apostar por la creatividad debe ser cada vez más prioritario para muchas escuelas, institutos y universidades, pero también debe atraer a personas, instituciones y empresas, y como no, a fundaciones, asociaciones y comunidades, pero creemos que puede y debe convertirse en un reto conjunto que nos conecte a todos a una meta común de construir una sociedad creativa. Esto solo es posible si cada uno desde su parcela aporta su potencial creativo individual y lo conecta con el colectivo. La creatividad va mucho más allá de tener ideas originales: es una forma de ser, de vivir, de vibrar, de relacionarse, de expresarse.

Somos conscientes de las inmensas posibilidades de la Inteligencia Artificial, el Big Data y los algoritmos. Pero, también conocemos los peligros de la posverdad, el hiperconsumismo y la incertidumbre que nos acompaña en estos tiempos sin certezas. En consecuencia, a la sociedad creativa se le presenta un gran reto: redimensionar la identidad del ser humano ante esta nueva realidad tan confusa.

Por esto, la humanidad se halla inmersa, es un escenario de experiencias extremadamente duras y dolorosas, muchas de las cuales ya son conocidas (pandemias, inundaciones, capitalismo salvaje, consumismo vehemente, daños al medio ambiente, e injusticia social, entre otras muchas amenazas). Necesitamos cambios transcendentales para impedir que la humanidad continúe el acelerado camino hacia el abismo.

El profesor BAUMAN $(2015,61)$, describe que es imparable el tributo que estamos pagando por el mal funcionamiento de una sociedad progresivamente indiferente, insensible, apática y despreocupada, una vez consumida por el virus de la adiaforización. Se pasa muy fácil del escandalo inicial al olvido, y se reduce la posibilidad de unir fuerzas para evitar futuros victimismos.

Hay que despertar de estos condicionamientos y tomar conciencia de que en el universo solo hay abundancia y que esta riqueza se expresa según la conciencia interior de cada persona. Tenemos que elegir y quizás sea esta acción uno de los pocos poderes que tenemos en este mundo de ilusión. De esta elección depende el resultado de nuestra actitud y experiencias en la sociedad creativa. No hay que olvidar que, la época newtoniana ha sido superado por la mecánica cuántica y la neurociencia ha descubierto la plasticidad del cerebro, y el lenguaje lineal ha dado paso al modelo digital.

Tenemos constancia que la mayoría de las instituciones educativas están operando por debajo de las mejores prácticas. En el siglo XXI tenemos que maximizar el aprendizaje permanente de los docentes, y ello lleva consigo, muchas horas de formación y aprender habilidades nuevas, si queremos 
brindar una alta calidad en el desempeño. La fuerza más poderosa para el cambio vive dentro de nosotros.

Tenemos la oportunidad de hacer que esta década pase a la historia como "los maravillosos años veinte" en los que los docentes fuimos capaces de reinventar la educación y ponerla al servicio de una Nueva Humanidad y del planeta. Lanzar esta visión proactiva quiero justificarla, sabiendo que tras las épocas destructivas suelen ser seguidas por épocas constructivas. Pienso que ya hemos empezado a construir los mimbres del nuevo paradigma.

En estos tiempos de grandes transformaciones sociales, las nuevas generaciones de docentes tendrán que conectar con la oleada creativa que está cruzando el planeta y dejar que sus efectos resuenen en el tejido emocional de la humanidad. En la próxima fase de nuestros proyectos propongo sincronizarnos y comprometernos a manejar tres pilares:

- CREAR UNA RED INTERNACIONAL DE ESTUDIOS CREATIVOS que nos permita estar conectados y conocer como alcanzar la excelencia creativa en nuestras competencias.

- VISUALIZAR EL PODER DE LOS SUEÑOS de tal forma que nos permita integrar los aspectos sociales, ambientales y de buen gobierno para una conciliación personal, profesional y familiar, y alcanzar un futuro sostenible

- APLICAR LA CAPACIDAD CREATIVA en todas las tareas propias para definir, mejorar y transformar nuestra cultura y desarrollar proyectos de cambios permanentes.

En síntesis, tenemos que comprender que, la agitación planetaria que estamos experimentando ahora no es un final, sino un nuevo comienzo, que ofrece la oportunidad de dar a luz una civilización nueva, una sociedad creativa, que asegurará que toda la vida tenga la oportunidad de progresar en el futuro, devolviendo a la naturaleza lo que es suyo, y reintegrando al ser humano en su lugar.

Es el momento de dirigir nuestras intenciones y nuestros esfuerzos para apoyar el surgimiento de una nueva humanidad holística, saludable y armoniosa. Quiero invitar a todos mis colegas a promover todos juntos un círculo virtuoso para ayudar a todas las instituciones educativas a fortalecer su imagen y prestigio, así como obtener una ventaja competitiva, generando valor económico, social y ambiental, que contribuya al desarrollo sustentable del territorio. 


\section{Referências}

BAUMAN Zygmunt (2013): Sobre la educación en un mundo líquido. Barcelona. Paidós.

(2015): Ceguera moral. Barcelona. Paidós.

y BORDONI, Carlo (2016): Estado de crisis. Barcelona. Paidós.

HAWKING Stephen (2018): Breves respuestas a las grandes preguntas. Barcelona Crítica.

MENCHEN BELLÓN, Francisco (2009): La Creatividad y las Nuevas Tecnologías en las Organizaciones modernas. Madrid. Díaz de Santos.

(2015): La necesidad de Escuelas creativas. Escuela Galáctica, Una Nueva Conciencia.

(2016) Revista "Dirigir Personas" No 28, II Época. Octubre 2016. AEDIPE (Asociación Española de Dirección y Desarrollo de Personas. Madrid.

(2019): Cómo capacitar excelentes docentes innovadores. El Sistema Creativo del ser humano. Madrid. Díaz de Santos.

(2020): El ADN del aprendizaje creativo. Redescubrir la creatividad como experiencia de vida. Madrid. Wolters Kluwer.

ORWELL, George (2018): 1984. Barcelona. Lumen

RIFKIM, Jeremy (1996): El Fin del trabajo: nuevas tecnologías contra puestos de trabajo: el nacimiento de una nueva era. Barcelona. Paidós.

(2000): La era del acceso. La revolución de la nueva economía. Barcelona. Paidós.

TORRE, Saturnino de la (Con la colaboración de MENCHÉN, Francisco; PUJOL, Ma Antonia y FORÉS, Anna) (2011): La adversidad esconde un tesoro. Otra manera de ver la adversidad y la vida. Sevilla. Círculo Rojo.

TORRE, Saturnino y INCHAUSTE, Jeannette (2019): Reaprender a vivir. Guía para superar ictus, cáncer, accidentes y enfermedades graves, convirtiendo la adversidad en oportunidad. Málaga. Aljibe.

https://sostenibilidadurbana.wordpress.com/tag/sociedad-creativa/ http://almeria.partidoequo.es/ceguera-moral-adiafora-mar-verdejo-coto/ 
Recebido em: 02 set. 2020

Aceito em: 07 dez. 2020 